\title{
SURFACE SUBSIDENCE FROM UNDERGROUND COAL MINING IMPACTING RESIDENTIAL HOUSING: A CASE STUDY OF RISK ANALYSIS, MITIGATION PROPOSAL AND ONGOING MONITORING
}

\author{
BRETT A. POULSEN \& BAOTANG SHEN \\ Commonwealth Scientific and Industrial Research Organisation, Australia
}

\begin{abstract}
Two subsidence events twenty years apart resulted in damage and destruction of residential housing near Ipswich in the state of Queensland, Australia. Led by the Australian governments, Commonwealth Scientific and Industrial Research Organisation, a research program was undertaken to determine the cause of subsidence, identify areas at risk, propose a stabilising technology and monitor the site. Site investigation including surface to void drilling, three-dimensional seismic survey, evaluation of historical mining data and interviews with ex-mine site personnel identified the most likely cause of subsidence as the over-stressing and failure of inadequately sized remanent coal pillars. It was concluded that water from the ongoing flooding of workings may have impacted pillar stability. A factor-of-safety evaluation of over 1,100 remanent coal pillars together with risk analysis of future surface subsidence was undertaken and identified another panel of the abandoned colliery that placed housing at unacceptable risk of future damage. An evaluation of bulk backfill identified a mitigation technology to ameliorate that risk. Continuous monitoring for over seven years by an instrument array of geophones, extensometers and piezometers has evaluated and reported the stability of strata overlying the colliery. This paper describes (1) the novel technique developed for evaluation of risk of surface subsidence for many hundreds of coal pillars accounting for the unique spatial and geometric attributes of every individual pillar. Included in the risk analysis study is water and time impacts on each pillars Factor of Safety (FoS); (2) mitigation technology developed for the stabilisation of pillars; and (3) the results of over seven years of strata monitoring.
\end{abstract}

Keywords: coal mining, surface subsidence, risk analysis, ground monitoring, bulk backfill.

\section{INTRODUCTION}

During the 19th and 20th centuries the "bord and pillar" method of underground coal mining was implemented in a number of mines near Newcastle (NSW) and Ipswich (Qld.) in Australia. Near Ipswich in Queensland an underground colliery produced thermal coal from a Triassic age thick coal seam from 1966 to 1987 [1]. Being an unusually thick seam of coal in this basin the average mining section was $6.1 \mathrm{~m}$ [2], ranging from $3 \mathrm{~m}$ to $12 \mathrm{~m}$ (Fig. 1).

A unique feature of the colliery is that it spans the introduction of the "modern" practice of designing coal pillars to a Factor of Safety (FoS) as expounded in the classic 1966 paper by Salamon and Munro [3] introduced after the Coalbrook mining disaster in 1960 [4]. Pillars in the western workings that predated the modern approach were designed to a $40 \%$ extraction ratio by plan and were typically of diamond shape with variable height and width and routinely robbed in an ad hoc manner to make tonnage as required. Pillars in the newer eastern workings were designed after mine management travelled to South Africa and are typically square in plan and designed to an average FoS of 1.6. Since mine closure two surface subsidence events over the western workings have occurred 20 years apart (Fig. 2).

This paper summarises several aspects of a research program undertaken by the Commonwealth Scientific and Industrial Research Organisation (CSIRO) of Australia and published in a series of papers [5]-[10]. CSIRO was tasked to undertake the following: 


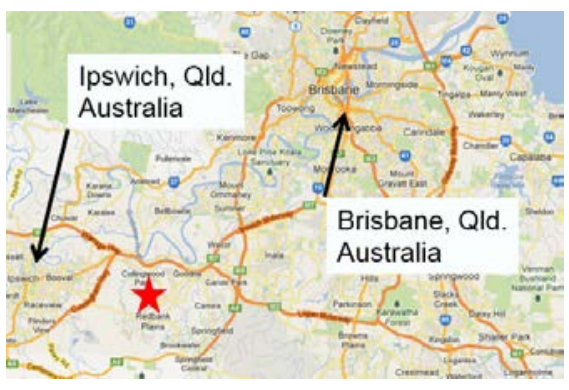

(a)

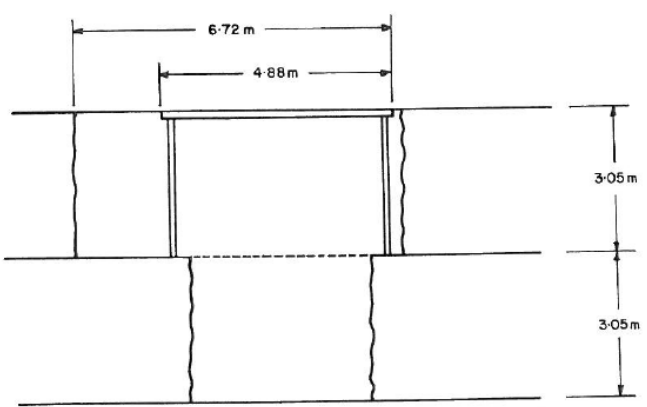

(b)

Figure 1: (a) Location map of colliery; (b) Typical mining section from [1].

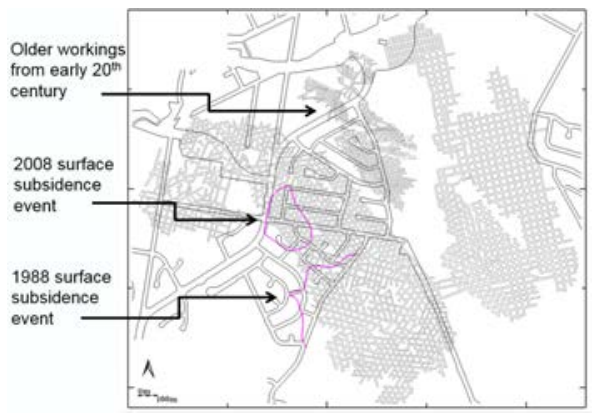

Figure 2: Mine workings with limit contour of surface subsidence.

- Determine the cause of the latest (2008) failure;

- Undertake a risk analysis of the remaining coal pillars;

- Recommend a mitigation strategy to reduce the risk of further subsidence; and

- Monitor the ground for stability and advise the state government of ongoing risk on a weekly or fortnightly basis. As of writing the on-going engagement between the CSIRO and state government has lasted 8 years.

The paper will concentrate on the risk analysis method developed during the project and results from nearly 8 years of monitoring ground conditions with a network of instruments including extensometers, piezometer and a micro seismic array.

\section{CAUSE OF SUBSIDENCE}

Surface subsidence above bord-and-pillar coal mines typically takes one of two forms; hard edged near circular "pot holes", "chimney" or "sink holes" are possible where the cover depth is generally less than 10 times extraction height although it has been experienced to 35 times extraction height in India [11]. Pot holes may form where the mine roof has collapsed, generally at a roadway intersection, and the bulking of the rock strata is insufficient to fill the developing void space before the failure intersects the ground surface. A second type of surface subsidence is the surface expression of the failure of a number of coal pillars which crush and collapse resulting in the overburden subsiding due to loss of support. This type of 
surface subsidence is typically trough or basin shaped, possibly with tension cracks but without an obvious "hole".

In the investigation of the collapse near Ipswich ex-mine personnel were interviewed and mining reports considered, the mine plan was digitised and examined, collapsed and stable regions were examined by downhole televiewer, 3D seismic and an investigation of water levels and gas content undertaken. As no physical access to the workings was possible, all investigation was done with remote techniques. Typical data from this investigation is presented in Fig. 3.

All indications from the site investigation were that the surface subsidence was due to the collapse of a panel of pillars. It is believed that a single pillar would have first failed and this local lack of support would have overloaded adjacent pillars with failure progressing until halted by unmined coal and significantly larger "barrier" pillars. Collapse of the roof rock strata would have progressed from seam level to the surface.

\section{RISK ANALYSIS}

A major component of CSIRO's engagement was to undertake a risk analysis to identify other regions at risk within the mines foot print [5], [7]. A risk analysis based on an FoS approach was considered appropriate with FoS defined as follows:

$$
\text { Factor of Safety = Pillar strength / Pillar stress. }
$$

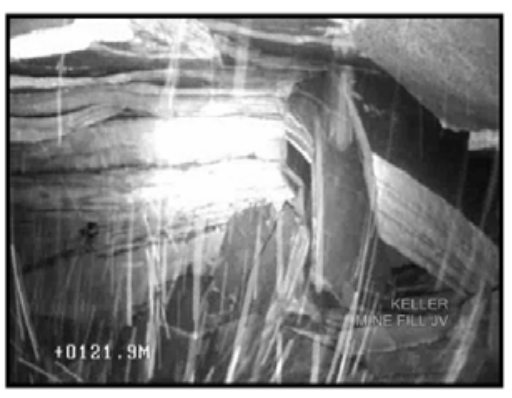

(a)

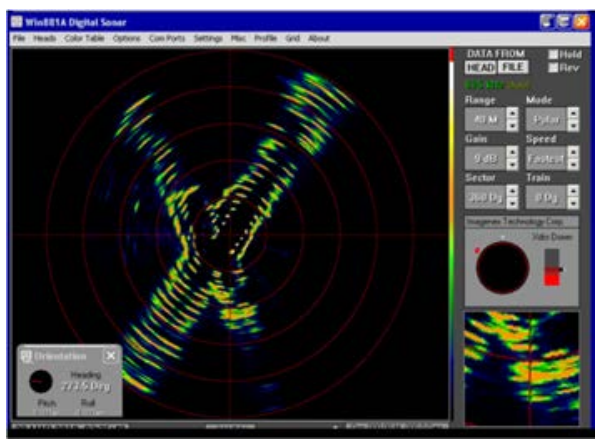

(c)

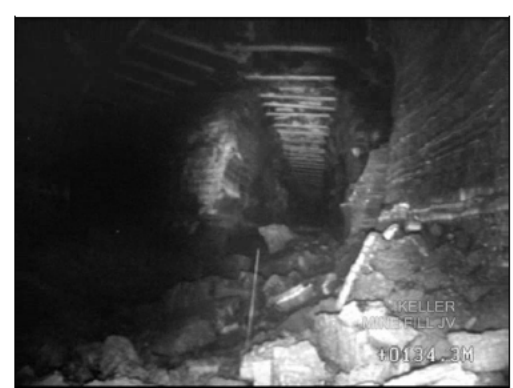

(b)

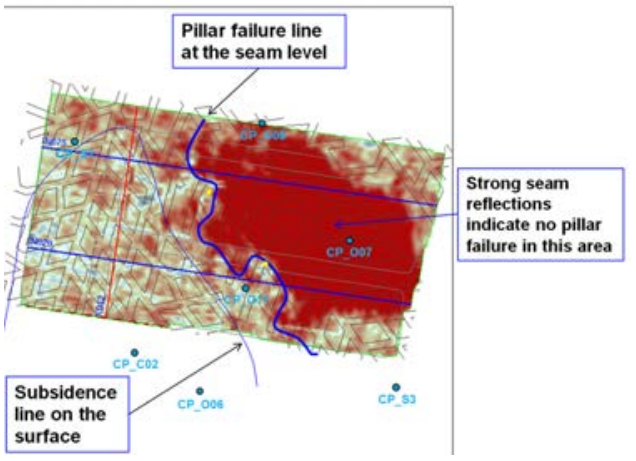

(d)

Figure 3: (a) Televiewer image of 2008 collapsed workings, (CP_006 in (d)); (b) Stable roadway with floor rubble (hole CP 007 in (d), 190 m from (a)); (c) Sonar imaging of intersecting roadways in flooded workings; (d) Interpretation of extent of failure at seam level from 3D seismic survey. 
In developing the risk analysis approach, several conditions were considered necessary as detailed below.

1. Every pillar (numbering greater than 1,100 ) should be considered.

2. Results should identify the two failure events known to have occurred in 1988 and 2008.

3. The methodology should be flexible enough to quantify potential remediation.

4. Impact of water, time and creep should be incorporated.

5. Failure of a single pillar would not have a surface expression, based on the work of others the failure of a panel of pillars of width equal or greater than the depth of cover (DoC) was considered necessary to result in surface subsidence.

Calculation of the two FoS components is outlined in the following sections.

\subsection{Calculation of pillar strength}

While a number of empirical equations estimate the strength of coal pillars the most widely used are based on a pillars width, $w$, and height, $h$. Of these empirical approaches the most famous is the method of Salamon and Munro [3] defined as follows in SI units:

$$
\text { Pillar strength }=7.2 w^{0.46} / h^{0.66} \text {. }
$$

A research project in led by the University of NSW, Australia updated this formula to local conditions by considering a data base of local failed and stable coal pillars. This modified formula can be expressed as follows:

$$
\text { Pillar strength }=8.6 w^{0.51} / h^{0.84} .
$$

When these formula, based on South African and Australian databases, are considered together and combined the results led the research authors to note that "there is remarkable consistency between the design formulas developed from back-analysis of the two separate national databases, containing many different coal seams and geological environments".

In developing eqns (2) and (3) the database of pillars included only square pillars. Several approaches are in common use for estimating an effective pillar width $\left(w_{e}\right)$ for non-square pillars.

$$
\mathrm{W}_{\mathrm{e}}=\mathrm{W}_{\min },
$$

and

$$
\mathrm{w}_{\mathrm{e}}=4 \mathrm{~A}_{\mathrm{p}} / \mathrm{C}_{\mathrm{p}},
$$

where $A_{p}=$ cross-sectional area of the pillar and $C_{p}=$ pillar circumference. Eqn (5) is appropriate for diamond shaped pillars as is typical in the western working of the colliery under consideration.

\subsection{Calculation of pillar stress}

Tributary area theory is routinely used in the calculation of the load applying on a coal pillar in the empirical FoS method however it has several necessary conditions. These include (1) that the pillar in regular in shape and surrounded by others of similar shape; and (2) that the pillar is not adjacent to unmined coal, barrier pillars or region of pillar collapse. It is obvious from inspection of the western workings in Fig. 2 that for the vast majority of these pillars neither of these necessary conditions are satisfied. An alternative analytical approach based on a local extraction ratio $e_{l}$ was developed and published in [5].

$$
\text { Pillar stress }=\rho g H /\left(1-e_{l}\right) \text {, }
$$


where for consistency with eqns (2) and (3) average overburden density $\rho=2488 \mathrm{~kg} / \mathrm{m}^{3}$, gravitational acceleration $g=10 \mathrm{~m} / \mathrm{s}^{2}$ and $H$ is DoC at the pillar centroid. The extraction ratio $e_{l}$ ranges from zero (no extraction) to 1 (100\% extraction). Eqn (6) is equivalent to tributary area theory when the necessary conditions for tributary area theory are satisfied.

In calculation of the local extraction ratio, the extent of "local" is based on a database of mining influences monitored in sedimentary strata. Abel [12] introduced the concept of a load transfer distance (LTD) in estimating the lateral extent of workings in flat lying sedimentary ore bodies. From a database of 55 measurements the LTD can be estimated as follows.

$$
\mathrm{LTD}=-0.0001 \mathrm{H}^{2}+0.2701 \mathrm{H},
$$

therefore a zone of influence (ZI) can be defined as the diameter of a circular region around a pillar of effective width $w_{e}$ as:

$$
\mathrm{ZI}=2 \mathrm{LTD}+\mathrm{w}_{\mathrm{e}} / 2
$$

Pillars within this zone of influence will be able to interact so that the failure of a single pillar will impact the load on adjacent pillars possibly leading to cascading pillar failure. In eqn (6) a local extraction ratio $e_{l}$ calculated on a pillar by pillar basis for each pillars ZI and therefore the calculation of pillar stress accounts for depth of cover, the geometric location of the pillar with respect to unmined coal and dynamic impact of adjacent pillar failure.

In the risk analysis code developed in this project a numerical method based on the digitised mine plan is developed to calculate the local extraction ratio. A Riemann integration is undertaken in two dimensions to calculate the void space and therefore the extraction ratio within the ZI of each pillar. Furthermore, digitisation of the mine plan allows access to the local DoC at each pillar centroid.

Further details are outlined in Poulsen [5] and Poulsen and Shen [7].

\subsection{FoS calculation for over 1,100 pillars}

From an examination of historical data together with the program of mine site investigation a total of 15 regions based on average pillar height were identified. Within these regions average pillar heights are estimated from 3.0 to $11.0 \mathrm{~m}$. This data together with DoC at pillar centroids was combined with an electronic version of the mine plan to estimate pillar strength from eqns (3) and (5).

From the FoS map (Fig. 4) it was concluded that the 1988 failure initiated further to the south east in an area of sporting fields and scrub land and then propagated to the north west before being halted by a panel of significantly larger pillars. By comparison it was concluded that the 2008 failure initiated with the failure of single pillar in the centre of a panel of marginal pillars. It is believed that this failure then spread outwards to encompass most, if not all of these pillars before being halted by unmined coal to the west and a large barrier pillar to the east.

Pillar failure at the scale that results in surface subsidence can be highly dynamic resulting in wind blasts and the mass trapping of personnel as happened at Coalbrook in 1960 when 437 people died. Progression of failure is due to the shedding of stress from a failed pillar to adjacent pillars possibly resulting in the overload, failure and a cascading of the failed region. Poulsen and Shen [7] outline the approach developed to account for these dynamic interactions in the FoS map as well as account for environment decay of the pillar with age. In Fig. 5 the FoS map of Fig. 4 is extended to show the final FoS distribution after stabilisation of the dynamic pillar interaction assuming initialising of failure for pillars with FoS $<1.0$. 


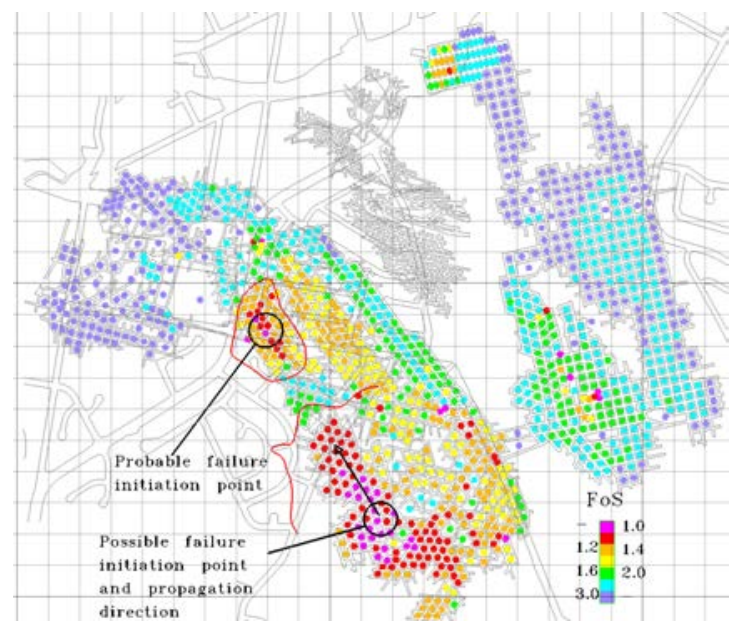

Figure 4: FoS map of over 1,100 pillars using the method of local extraction ratio to account for the pillars spatial location wrt unmined coal, barrier pillars and adjacent pillars.

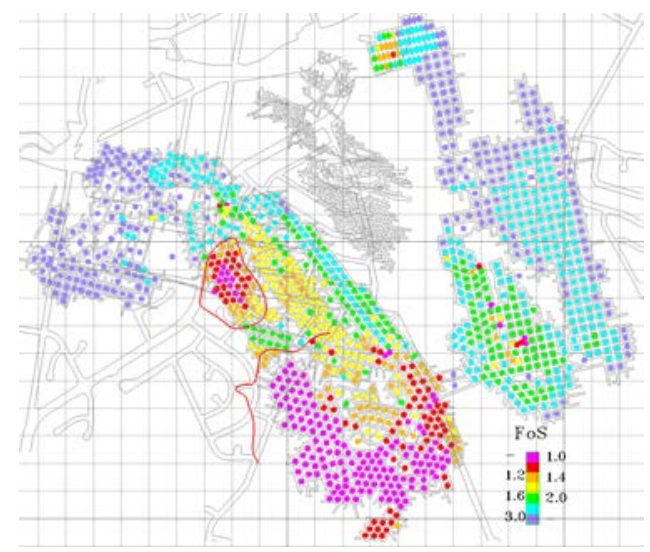

Figure 5: FoS map with load shedding and dynamic interaction between pillars.

\subsection{Risk mapping}

In developing a risk map for residential housing from further surface subsidence the probabilities of failure associated with eqn (3) (Table 1) was combined with an estimate of consequence developed in consultation with local government (Table 1 (right)). This consequence was expressed in terms of surface tilt ranging from $<5 \mathrm{~mm} / \mathrm{m}$ to $>20 \mathrm{~mm} / \mathrm{m}$ with details outlined in Poulsen and Shen [7].

To fully develop surface subsidence requires the failure of pillars over a plan region approximately equal to, or greater than, the depth of cover. We have assumed that there is a high probability of surface subsidence if $80 \%$ of pillars in the area below a surface point have a FoS $<1.6$. The "area below" a surface point is defined as a circular region of radius H/2. 
Table 1: Probability of failure associated with eqn (3) and risk matrix against surface subsidence proposed for the residential suburb.

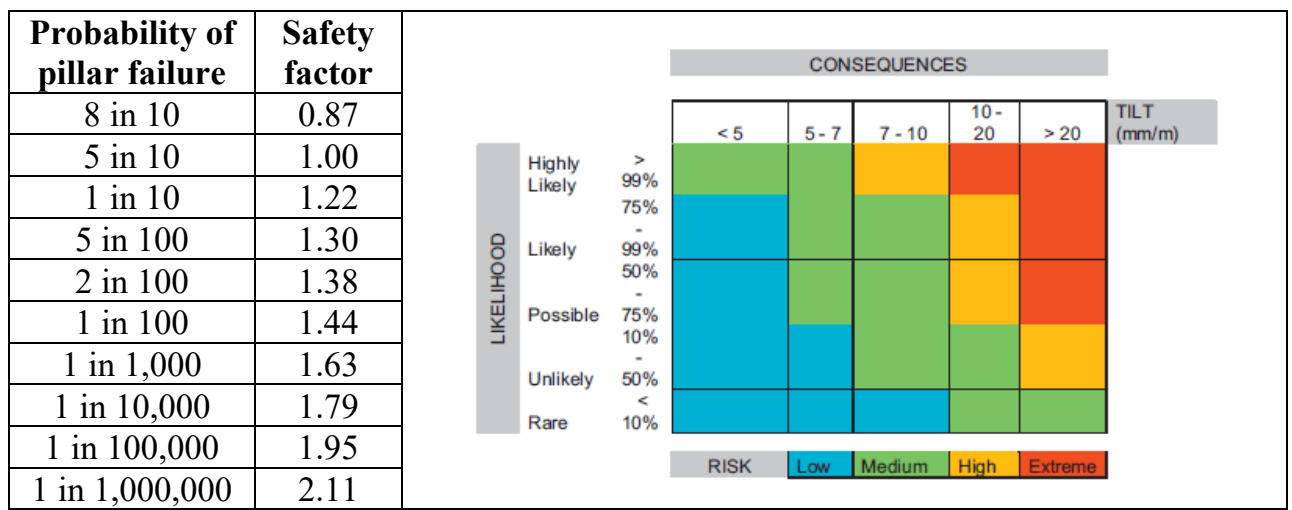

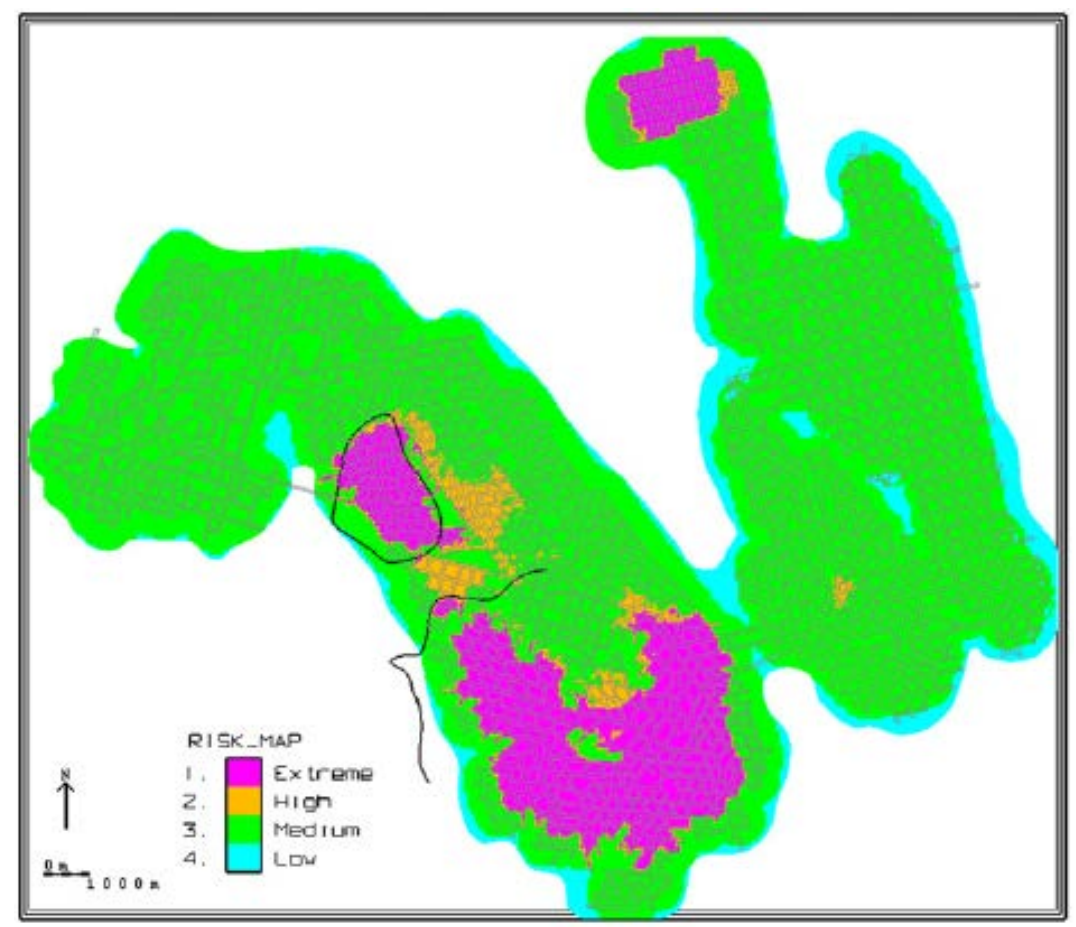

Figure 6: Risk map for surface subsidence with contour limits of two failure events [7].

Using the dynamic method for calculating the FoS a Monte Carlo simulation is undertaken sampling both the estimated pillar height and effective width (modified by environmental degradation) from the appropriate distributions. In the final risk map highlight in Fig. 6, it is assumed that the consequence of failure is consistent over the entire foot print of the mine. In practice this is not the case with local land use encompassing housing, sporting fields and bush lands. 
From the risk analysis just described, a region immediately to the east of the 2008 failure area was identified as being at an unacceptable risk level. This region described as the central panel, was to be the focus of stability monitoring and could be the target for stabilisation with backfill.

\section{MITIGATION PROPOSAL}

To mitigate the risk of future surface subsidence the use of fly ash from a nearby power station was investigated. Laboratory tests were conducted to characterise and assess the physical and mechanical properties of the ash which had an average particle size around $50 \mu \mathrm{m}$ and average solid particle specific gravity of 1.8 .

Density of the fly ash slurry with a solid concentration in the range $20-60 \%$ was found to range from $1.1-1.4 \mathrm{~kg} / \mathrm{cm}^{3}$ increasing to $1.6 \mathrm{~kg} / \mathrm{cm}^{3}$ with compaction and consolidation.

A series of tests including horizontal passive strength, vertical bearing strength and slope test in submerged conditions (to replicate flooded mine works) determined the ash to have an internal friction angle of approximately $42^{\circ}$.

A series of tests investigated the undrained and consolidated stiffness of the fly ash. It was found that the undrained modulus of the saturated ash was high at approximately $2.2 \mathrm{GPa}$ but that this reduced to as low as $1 \mathrm{MPa}$ in drained conditions. Stiffness of a normally consolidated ash under consolidation pressure of $1 \mathrm{MPa}$ was found to be approximately 10 $20 \mathrm{MPa}$ and consolidation tests determined that full consolidation of a deep $(10 \mathrm{~m}+)$ column required several years to develop.

The effectiveness of fly ash as a backfill depends on the ability of the ash to flow and fill all available void space. To test flow ability a testing tank of dimensions $3 \mathrm{~m}$ x $2 \mathrm{~m} \times 0.5 \mathrm{~m}$ was constructed with a typical layout of appropriately scaled pillars and the ability to simulate seam dips from $0^{\circ}$ to $10^{\circ}$. Ash concentrations from $45 \%$ to $62 \%$ were studied and the velocity of injection required to avoid blockage was found to be around $0.046 \mathrm{~m} / \mathrm{s}$ for $65 \%$ concentration. It was found that boundary conditions influence the settled ash beach angle; with $50 \%$ solids concentration and with an initial layer of settled ash, it was found that the beach angle was less than $1^{\circ}$. Beach angle is important as the higher the gradient the more filling boreholes is required and there is an increase in the likelihood of blockage and unfilled void space (Fig. 7).

Extensive investigations were undertaken on the chemistry and leaching potential of ash samples. Both toxicity characteristics leaching procedure (TCLP) and synthetic groundwater leaching protocol (SGLP) tests were undertaken with full details presented in Shen et al. [10].

In conclusion, from the laboratory tests undertaken, it was found that fly ash backfill with a $50 \%$ solids concentration had excellent flowability and very low viscosity. It was capable
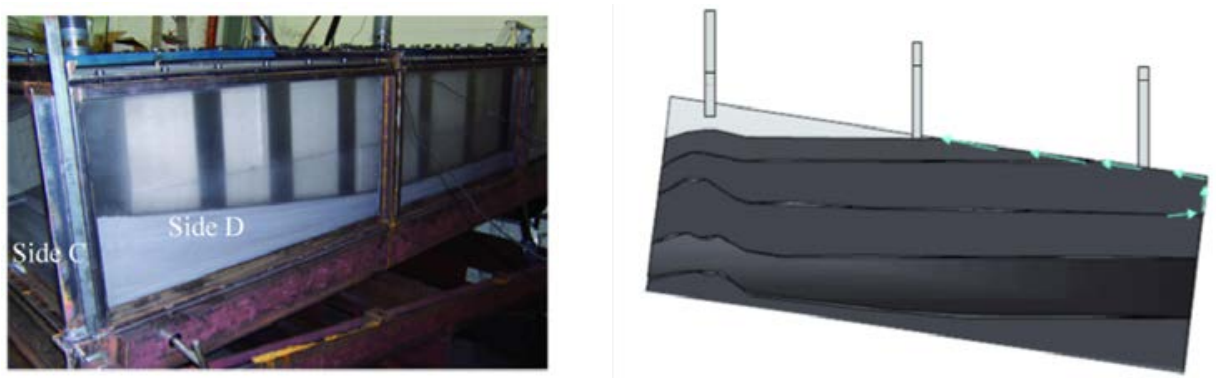

Figure 7: Flowability studies in test tank. Initial filling (left) and schematic of tank (right) with flow vectors showing ash movement with filling. 
of penetrating and filling almost any void underground and settled as a reasonably stiff solid to provide support to pillars. From several types of strength test the angle of internal friction of the settled ash is estimated as $42^{\circ}$ or greater. Numerical simulations discussed in Hongwei et al. [6] indicate that $90 \%$ backfill could raise the FoS of a marginally stable pillar to above 1.6. Chemistry and leachate analysis indicates the elemental concentration of the proposed backfill is lower than the allowable contaminant thresholds and specific contaminant concentrations levels.

\section{SITE MONITORING}

At the time of writing in 2017, continuous monitoring of the site has been undertaken for seven years with the focus being on the central panel, an area of interest identified from risk analysis. An array of geotechnical instruments quantify the stability of the rock strata and provide early-warning capacity until remediation methods can be deployed. The following instruments have been deployed on site.

- Deep hole extensometers. These instruments extend from the surface to near the mining seam, a distance of $100 \mathrm{~m}$ and more. Spread along this line at varying depths are multiple anchors which are monitored at the head frame for movement. Any local ground movement due to the failure of rock strata from pillar collapse will first impact the lower most anchor and progress upwards over time.

- Micro seismic array. Ten tri-axial geophones are distributed in 4 boreholes at varying depths. Similar to seismic stations that record earthquakes, the micro seismic array is sensitive to the breakage of rock which can be recorded to a distance that is dependent on the energy released by the event. To date small releases of energy associated with local rock breakage have been recorded approximately $600 \mathrm{~m}$ from the focal point of the array while a magnitude 7.9 earthquakes was recorded over a distance greater than $2400 \mathrm{~km}$. Locating the events in plan and elevation is possible when sufficient event energy triggers multiple geophones.

- Piezometers. These instruments measure the water level and are installed in both the focus colliery together with a nearby historical colliery that is 60 years older. As most coal seams are aquifers, with mine closure and the cessation of pumping the mine is slowly flooding. Water is known to impact pillar stability and the movement of water thru the central panel has been closely monitored.

Only a very brief overview of seven years of data is possible here. Fig. 8 displays the estimated water levels at the time of the two subsidence events in 1988 and 2008 together with measured water levels in the years since. From 2008 till 2012 water rose through the central panel a time of concern as it is known that coal and rock lose strength with saturation [8]. This strength loss is associated with the lubrication of natural discontinuities and bedding together with the degradation of clay minerals in the strata. From 3D numerical studies it was estimated that the strength of a typical coal pillar in the study mine may be reduced by approximately $20 \%$ with saturation.

It was this period, from the start of monitoring in May 2010 to approximately the middle of 2012 that the greatest number of micro seismic events were recorded (Fig. 9). An association of micro seismic events with the water front was observed (Fig. 10(b)). In the cumulative event plot (Fig. 10(a)) it can be seen that events of sufficient energy to be located are clustered around the northern limit of the 2008 subsidence region. This suggests that the stress redistribution and strata settlement took several years to stabilise after the subsidence event. 


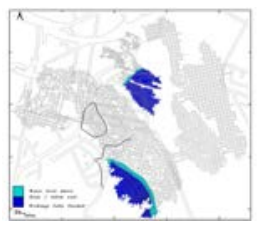

1988

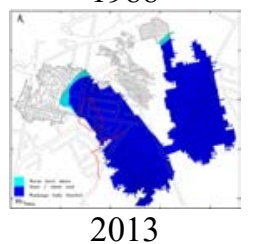

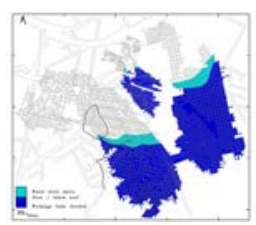

2008

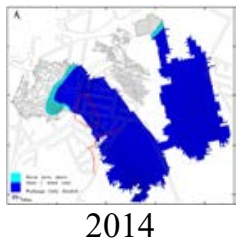

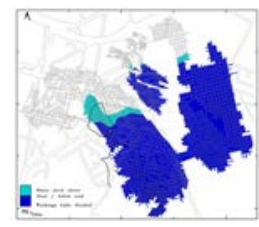

2011

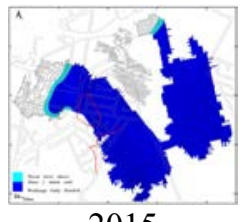

2015

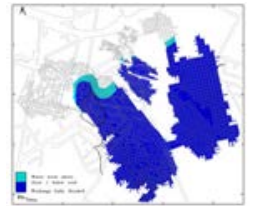

2012

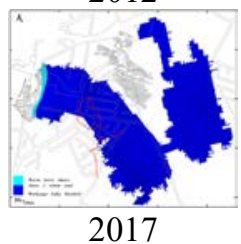

Figure 8: Water levels with time, estimated in 1988 and 2008 then as monitored. Initial subsidence event occurred in 1988 and second in 2008. Light blue region indicates water level between floor and roof while dark blue indicated water filled to roof.

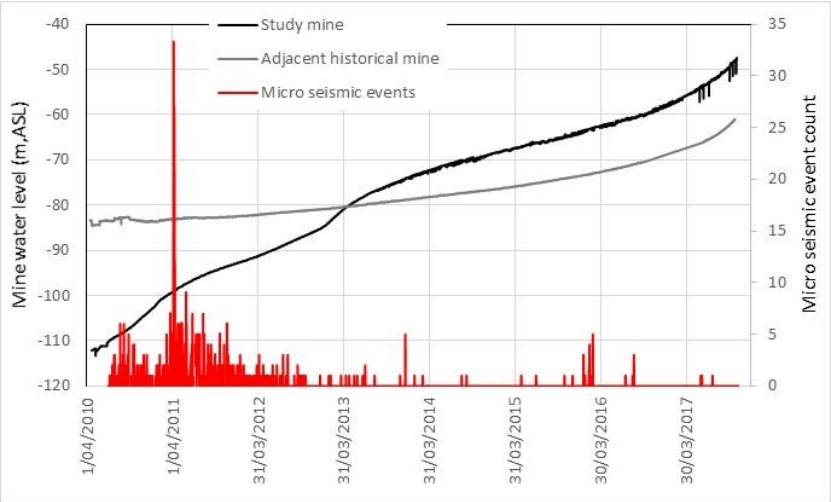

Figure 9: Measured water levels in the study mine and adjacent historical mine together with recorded micro seismic events.

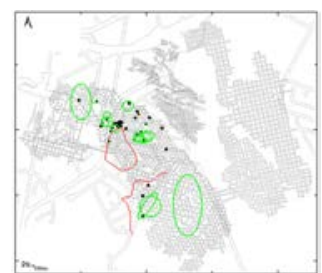

(a)

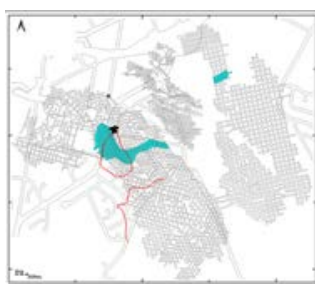

(b)

Figure 10: (a) Total located micro seismic events to date identified as black dots and approximate event location for those events of insufficient energy to be properly located; (b) Events recorded with sufficient energy to be located in 2011 with the approximate location of the water front in May 2011. 


\section{CONCLUSION}

An ongoing research project of a high risk abandoned coal mine has been described. The project has developed several novel risk assessment and control technologies including an empirical and analytical approach to calculating the FoS of in excess of 1,100 pillars. This method accounts for the spatial position of the pillar in the mine and the dynamic interaction of adjacent pillars and forms the basis for the risk analysis.

For remediation of the panel identified as at risk, a bulk backfill based on fly-ash was developed. With a solids concentration of $50 \%$ the grout is shown to have excellent flowability and very low viscosity in laboratory trials. The grout demonstrated the ability to penetrate and fill most underground voids if properly designed, settling to a reasonably stiff solid to provide support and confinement to the pillars.

Geotechnical monitoring of the areas identified as at risk has been underway for over seven years with an extensive array of early warning instruments providing extensive coverage. By the regular analysis of monitoring data and reporting to the parties concerned of strata stability in a timely manner the risk of a further unexpected subsidence event has been reduced.

\section{ACKNOWLEDGEMENTS}

This project was sponsored by the Queensland State Government Department of Natural Resources (DNRM). We would like to thank the contributions of Damian Lewis and Ian Gould and our colleagues at the CSIRO to this study.

\section{REFERENCES}

[1] Edgar, J., Thick seam mining as practised at Westfalen colliery, Qld. The Australian Institute of Mining and Metallurgy Symposium, 1976.

[2] Kathage, W.A., Roof control associated with a borer miner and multiple slicing in thick seams at Westfalen No. 3 mine. The Australian Institute of Mining and Metallurgy Symposium, 1980.

[3] Salamon, M.D.G. \& Munro, A.H., A study of the strength of coal pillars. South African Institute of Mining and Metallurgy, 68, pp. 56-67, 1967

[4] van der Merwe, J.N., Beyond Coalbrook: what did we really learn? South African Institute of Mining and Metallurgy, 106, 2006.

[5] Poulsen, B.A., Coal pillar load calculation by pressure arch theory and near field extraction ratio. International Journal of Rock Mechanics and Mining Sciences, 47, pp. 1158-1165, 2010

[6] Hongwei, W., Poulsen, B.A., Shen, B., Xue, S. \& Jiang, Y., The influence of roadway backfill on the coal pillar strength by numerical investigation. International Journal of Rock Mechanics and Mining Sciences, 48, pp. 443-450, 2011.

[7] Poulsen, B.A. \& Shen, B., Subsidence risk assessment of decommissioned bord-andpillar collieries. International Journal of Rock Mechanics and Mining Sciences, 60, pp. 312-320, 2013.

[8] Poulsen, B.A., Shen, B., Williams, D.J., Huddlestone-Holmes, C., Erarslan, N. \& Qin, J., Strength reduction on saturation of coal and coal measures rocks with implication for coal pillar strength. International Journal of Rock Mechanics and Mining Sciences, 71, pp. 41-52, 2014.

[9] Shen, B. \& Poulsen, B., Investigation of overburden behaviour for grout injection to control mine subsidence. International Journal of Mining Science and Technology, 24, pp. 317-323, 2014. 
[10] Shen, B., Poulsen, B., Xun, L., Qin, J., Thiruvenkatachari, R. \& Yi, D., Remediation and monitoring of abandoned mines. International Journal of Mining Science and Technology, 27, pp. 803-811, 2017.

[11] Lokhande, R.D., Murthy, V.M.S.R. \& Singh, K.B., Pot-hole subsidence in underground coal mining: some Indian experiences. Geotechnical and Geological Engineering, 31, pp. 793-799, 2013.

[12] Abel, J.F. Jr., Soft rock pillars. International Journal of Mining and Geological Engineering, 48, pp. 215-248, 1988. 